\title{
Role of macrophage and smooth muscle cell apoptosis in association with oxidized low-density lipoprotein in the atherosclerotic development
}

Yuri Akishima ${ }^{1}$, Yoshikiyo Akasaka ${ }^{1}$, Yukio Ishikawa ${ }^{1}, Z_{\text {Zhang Lijun }}{ }^{1}$, Hideko Kiguchi ${ }^{2}$, Kinji Ito ${ }^{1}$, Hiroyuki Itabe ${ }^{3}$ and Toshiharu Ishii ${ }^{1}$

${ }^{1}$ Department of Pathology, Toho University, School of Medicine, Tokyo, Japan; ${ }^{2}$ Department of Pathology, Saiseikai Kanagawaken Hospital, Yokohama, Japan and ${ }^{3}$ Department of Biological Chemistry, School of Pharmceutical Sciences, Showa University, Japan

\begin{abstract}
To examine the role of the apoptosis of macrophages and smooth muscle cells in the development of atherosclerosis, human aortic tissues with intimal lesions were immunostained with antibodies against terminal deoxynucleotidyl transferase (TdT)-mediated dUTP-biotin nick end labeling (TUNEL), single-stranded DNA (clone F7-26), and active caspase-3. Apoptotic cells were detected in the intima using both TUNEL and singlestranded DNA, however, the latter method was the more sensitive one for detecting apoptotic cells in the early stages of atherosclerosis. The number of apoptotic cells increased as the disease progressed. It implies that the apoptosis of intimal cells is involved in the formation of atherosclerotic lesions. In addition, quantitative analyses of the cell types undergoing apoptosis using double-immunostaining revealed that the susceptibility of macrophages and smooth muscle cells to apoptosis was greater specifically in atheroma than in the other atherosclerotic lesions, and macrophages were more susceptible to apoptosis than smooth muscle cells. The frequency and spatial distribution of oxidized low-density lipoprotein (oxLDL) (FOH1a/DLH3)-positive cells were examined by immunohistochemistry, and the results resembled those of apoptotic cells. The number of oxLDLpositive cells in the intima significantly correlated with the susceptibility of smooth muscle cells, but not with that of macrophages, to apoptosis. These results suggest that oxLDL affects the apoptosis of smooth muscle cells during the atherosclerotic development.
\end{abstract}

Modern Pathology (2005) 18, 365-373, advance online publication, 20 August 2004; doi:10.1038/modpathol.3800249

Keywords: apoptosis; atherosclerosis; oxidized low-density lipoprotein (oxLDL); single-stranded DNA; TUNEL

Atherosclerosis begins with endothelial dysfunction and increase adherence of monocytes/macrophages and $\mathrm{T}$ lymphocytes. Then, monocyte/macrophage infiltration in the subendothelial space accompanied by serum lipid permeation and the migration of medial smooth muscle cells into the intima. ${ }^{1}$ Macrophages and smooth muscle cells become foam cells as a result of lipid phagocytosis, and a fatty streak, a macroscopically identifiable intimal lesion, is formed in the affected intima. ${ }^{2}$ Fatty streak can develop into advanced lesions, such as atheroma, and subsequently complicated lesions over several decades. ${ }^{1,3,4}$ Various risk factors, such as hyperten-

Correspondence: Y Akishima, 5-21-16 Omori-Nishi, Ota-Ku, Tokyo 143-8540, Japan.

E-mail: akiyuri@med.toho-u.ac.jp

Received 4 March 2004; revised and accepted 11 June 2004; published online 20 August 2004 sion, hypercholesterolemia, cigarette smoking, diabetes mellitus, genetic alterations, and familial predisposition affect the progression of atherosclerosis. ${ }^{3,5}$ It is recognized that apoptosis takes place in atherosclerotic lesions, and that the rate of apoptosis varies $(<2-30 \%) .^{6-9}$ The pathophysiological roles of apoptosis in atherosclerosis have been discussed in conjunction with cell distribution and type as well as with plaque stabilization, plaque rupture, and regression of thickened arterial walls. ${ }^{7,10-13}$ Apoptotic cells are usually identified by morphological observation using terminal deoxynucleotidyl transferase (TdT)-mediated dUTP-biotin nick end labeling (TUNEL). ${ }^{5}$ However, single-stranded DNA monoclonal antibody developed recently is further sensitive enough to detect from the beginning of apoptosis. ${ }^{14,15}$

Oxidized low-density lipoprotein (oxLDL) is now considered to play a significant role not only in 
atherogenesis but also in the entire process of atherosclerosis such as the formation of foam cells and the fatty streak, and induction of smooth muscle cell migration and proliferation. ${ }^{16-18}$ In addition, oxLDL is cytotoxic to cultured cells and induces both apoptosis and necrosis of cultured smooth muscle cells. ${ }^{19}$ In 1994, Itabe et $a l^{20}$ raised a monoclonal antibody directed against oxLDL (FOH1a/DLH3) to investigate whether oxLDL was synthesized in foam cells in vitro and in vivo. ${ }^{20-23}$ Despite the close relationship between the level of oxLDL expression and the induction of apoptosis, there have been only a few studies in vivo on the role of oxLDL in the apoptosis of intimal cells. ${ }^{9,11}$ Furthermore, the difference in distribution of apoptosis between smooth muscle cells and macrophages has not yet been examined with respect to atherosclerosis.

In the present study, the frequency and spatial distribution of apoptotic macrophages and smooth muscle cells in initial lesions during the progression of atherosclerosis were examined by immunohistochemistry using a single-stranded DNA (F7-26) monoclonal antibody, an active caspase-3 polyclonal antibody, and TUNEL. An attempt was also made to explore the significance of oxLDL in promoting atherosclerosis through apoptosis with quantitative analyses of the association between the level of oxLDL expression and the apoptosis of both macrophages and smooth muscle cells.

\section{Materials and methods}

\section{Materials}

Aortic tissues were obtained at autopsy from 21 patients (15 males and 6 females), ranging in age from 47 to 96 (mean \pm s.d., $71.1 \pm 12.2$ ) years old at the Department of Pathology, School of Medicine, Toho University. Written informed consent to use the tissues was provided by the patients' relatives. A total of 78 aortic tissues having no macroscopic atherosclerotic portions or having atherosclerotic lesions were taken from the thoracic and abdominal aortas. They were fixed in 10\% neutral-buffered formalin and embedded in paraffin. Thin sections were treated with hematoxylin-eosin and elastic van Gieson’s stain.

\section{Classification of Intimal Lesions}

The atherosclerotic lesions were divided into eight categories according to the AHA microscopic classification: ${ }^{2,24,25}$ normal, diffuse intimal thickening, initial lesion, fatty streak, preatheroma, atheroma, fibroatheroma, complicated lesion, and calcified lesion (Table 1). ${ }^{26}$ In the present study, 'normal' refers to an aorta without any intimal lesions. Diffuse intimal thickening is an atherosclerosisprone condition, but one in which smooth muscle cells infiltrate the intima with an increase in extracellular matrices. Initial lesion contains an increased number of foamy macrophages scattered in the intima. Fatty streak consists of an aggregation of foam cells derived from macrophages and/or smooth muscle cells, and is a precursor of advanced lesions. ${ }^{25,27}$ Preatheroma is an intermediate lesion between fatty streak and atheroma characterized by extracellular lipid deposition. Atheroma contains a lipid core with a fibrocellular covering, while fibroatheroma additionally has a thick fibrous cap covering the lipid core. Complicated lesion is composed of superimposed features of atheroma and fibroatheroma with disruption, hematoma, thrombosis, or calcification. Each specimen was, thus, classified into one of five broad lesion groups for statistical analysis: Group I $(n=13$; normal, diffuse intimal thickening, and initial lesion), Group II $(n=21$; fatty streak), Group III $(n=17$; preatheroma), Group IV ( $n=15$; atheroma), and Group V ( $n=12$; fibroatheroma and complicated lesions).

\section{Immunohistochemistry}

In this study, we employed an immunohistochemical method using a single-stranded DNA monoclonal antibody (clone F7-26, Chemicon Int. Inc., Temecula, CA, USA). Single-stranded DNA staining was carried out as follows. In brief, thin sections were placed in $0.12 \%$ polyoxyethylene (20) sorbitan monolaurate (Wako Pure Chemical Industries, Ltd.,

Table 1 Classifications of atherosclerotic lesions used in pathology

\begin{tabular}{|c|c|c|c|}
\hline \multicolumn{2}{|c|}{ Histological classification of lesions } & \multicolumn{2}{|c|}{ Additional terms (often based on appearance with the unaided eye) } \\
\hline Type I & Isolated macrophage foam cells & Fatty dot, fatty streak & Early lesion, minimal lesion \\
\hline Type II & Multiple foam cell layers & & \\
\hline Type III & Preatheroma, intermediate lesion & & \\
\hline Type IV & Atheroma & Fibrolipid plaque, Fibrous plaque, & Advanced lesion, raised lesion \\
\hline Type V & Fibroatheroma & plaque & \\
\hline Type VI & $\begin{array}{l}\text { Fissured, ulcerated, hemorrhagic, thrombotic } \\
\text { lesion }\end{array}$ & Complicated lesion & \\
\hline Type VII & Calcific lesion & Carcified lesion & \\
\hline Type VIII & Fibrotic lesion & & \\
\hline
\end{tabular}


Osaka, Japan) for $20 \mathrm{~min}$, and treated with $0.02 \%$ Proteinase K (Dako, Glostrup, Denmark) for $20 \mathrm{~min}$. After being rinsed with phosphate-buffered saline (PBS), they were incubated with 50\% formalin (56$60{ }^{\circ} \mathrm{C}$ ) in a water bath for $20 \mathrm{~min}$. They were treated with ice-cold PBS and $3 \% \mathrm{H}_{2} \mathrm{O}_{2}$, and then $3 \%$ nonfat dry milk in PBS to prevent nonspecific protein blocking. Sections were next incubated with the single-stranded DNA (F7-26) monoclonal antibody (dilution, 1:50) for $60 \mathrm{~min}$. They were then reacted with peroxidase-conjugated rabbit anti-mouse immunoglobulins (1:40; Dako) for $40 \mathrm{~min}$. The reaction products were visualized by treating the slide with 3,3'-diaminobenzidine tetrahydrochloride (DAB Liquid System, Dako) and counterstained with hematoxylin. TUNEL staining was also performed using a commercial kit (Takara, Tokyo, Japan). In order to examine the specificity of the singlestranded DNA (F7-26) antibody and TUNEL, we performed immunohistochemical staining with these antibodies in additional sections as controls (normal human prostate tissues and human hepatic tissues showing coagulative necrosis). The expression of single-stranded DNA (F7-26) and TUNEL were detected in the nuclei in the former tissues, but not observed in the latter tissues.

The streptavidin-biotinylated peroxidase complex method (LSAB 2 kit; Dako) was used for immunostainings with the following antibodies: anti-human macrophage monoclonal antibody (HAM56, dilution, 1:100; Dako), anti-alpha-smooth muscle actin monoclonal antibody (clone 1A4, 1:50; Dako), the large fragment of active caspase-3 (D175) polyclonal antibody (1:100; Cell Signaling Technology Inc., Beverly, MA, USA), ${ }^{28}$ and anti-oxLDL (FOH1a/ DLH3 $)^{20}$ monoclonal antibody (1:100). The each primary antibody was incubated for $60 \mathrm{~min}$, and the LSAB2 kit was used according to the manufacturer's instructions.

\section{Typing of Apoptotic Cell}

For identification of the type of each apoptotic cell, double-immunostaining was performed using single-stranded DNA (F7-26) antibody combined with HAM56 antibody or with alpha-smooth muscle actin antibody. In brief, after single-stranded DNA (F7-26) immunostaining with visualization by DAB, the sections were rinsed in $0.1 \mathrm{M}$ glycine-HCl buffer (pH 2.2) for $60 \mathrm{~min}$. After a rinse with Tris-buffered saline (TBS), they were immunostained with HAM56 antibody or alpha-smooth muscle actin antibody. The dilution and incubation times of the three antibodies were same as the above. The sections were then treated with alkaline phosphatase (BCIP/NBT Substrate system; Dako) for visualization of the latter antigens. The negative control consisted of incubation with immunoglobulin of the same species at the same final concentration without primary antibodies.

\section{Histomorphometric Methods}

In the present study, cells positive for singlestranded DNA (F7-26) and exhibiting at least one morphological feature of apoptosis such as cell shrinkage, the aggregation of chromatin into dense masses or cell fragmentation, were defined as apoptotic.

The determination and counting of immunopositive cells in all the specimens were performed by three pathologists (YA, YA, and YI) in a blinded manner, and repeated three times. The mean values \pm s.d. of these results were tallied.

\section{Statistical Analyses}

For statistical analyses, all the specimens immunostained with single-stranded DNA (F7-26) antibody, active caspase- 3 antibody, TUNEL, and oxLDL antibody were observed by light microscopy at highpower magnification $(\times 400)$. The number of the cells positive for these antibodies was counted for a total of 10 neighboring high-power view-fields $(\times 400)$ including the center of a given type of atherosclerotic lesions. The positive signal of singlestranded DNA, active caspase-3, and TUNEL was shown in the nuclei, and the positive signal of HAM56, alpha-smooth muscle action, and oxLDL was shown in the cytoplasm. The average number of positive cells for each antigen per one microscopic view-field was then calculated, and such value was compared among the five lesion groups. Associations of the average number of positive cells for each immunogen with the intimal lesion groups were analyzed using Scheffe's test.

The percentage of both single-stranded DNA and HAM56-positive cells to HAM56-positive cells in each group was designated as the apoptotic macrophage index, and the percentage of both singlestranded DNA and alpha-smooth muscle actinpositive cells to alpha-smooth muscle actin-positive cells as the apoptotic smooth muscle cell index. Student's $t$-test was used to compare the apoptotic macrophage index with the apoptotic smooth muscle cell index values in each lesion group and the average number of the apoptotic macrophage index in all lesion groups with the average number of the apoptotic smooth muscle cell index. The correlation of the average number of oxLDL-positive cells per microscopic view-field with the apoptotic macrophage index in apoptotic macrophages in 37 specimens was analyzed by linear regression. The correlation between the average number of oxLDL-positive cells per view-field and the apoptotic smooth muscle cell index for apoptotic smooth muscle cells in 32 specimens was analyzed similarly.

All analyses were carried out with the StatView software package (Abacus Concepts, Berkeley, CA, USA). A $P$-value less than 0.05 was considered significant. 


\section{Results}

\section{Immunohistochemistry}

\section{Group I lesion}

In the normal intima, cells positive for singlestranded DNA, active caspase-3, TUNEL, HAM56, alpha-smooth muscle actin, and oxLDL were absent. In the intima with diffuse intimal thickening, a few cells were positive for single-stranded DNA, active caspase-3, HAM56, or alpha-smooth muscle actin. TUNEL- or oxLDL-positive cells were absent among intimal cells. In the intimas with initial lesion, alpha-smooth muscle actin-positive cells as well as a few HAM56-positive cells were detected but positive signals for single-stranded DNA and active caspase-3 were very weak. OxLDL-positivity was detected in a few intimal cells. Doubleimmunostaining revealed a few single-stranded DNA-positive cells with positivity for alpha-smooth muscle actin or HAM56 in subendothelial spaces of the intima.

\section{Group II lesion}

Single-stranded DNA, active caspase-3, and TUNELpositive signals were sporadically detected in the nuclei of intimal foam cells (Figure 1a and b). They were more extensive in Group II than Group I lesions. HAM56-positivity was found in foam cells aggregating in the intimal lesion, and most of them also exhibited immunopositivity for oxLDL (Figure 1c). Alpha-smooth muscle actin-positive cells were observed mainly in the region of foam cell aggregation in the intima. By double-immunostaining, most single-stranded DNA-positive cells were found to be positive for HAM56 (Figure 1d), and a few singlestranded DNA-positive cells were positive for alphasmooth muscle actin.

\section{Group III lesion}

In this lesion, HAM56- and alpha-smooth muscle actin-positive cells were widely scattered in the intima. Single-stranded DNA, active caspase-3, and TUNEL signals were detected in the nuclei of intimal cells mainly around extracellular lipid deposits and in subendothelial spaces. By doubleimmunostaining, these cells were found to be positive for HAM56 or alpha-smooth muscle actin. OxLDL was recognized in intimal cells, most of which were foam cells around extracellular lipid deposits.

\section{Group IV lesion}

Single-stranded DNA was observed in the nuclei of many intimal cells, which were present around the lipid core including both the shoulder and fibrous cap portions of the atheroma lesion. A few single-stranded DNA-positive cells were also found in the lipid core. By double-immunostaining, single-stranded DNA-positive cells around the lipid core were mainly positive for HAM56
(Figure 2a), and single-stranded DNA-positive cells with alpha-smooth muscle actin expression were found mainly in the fibrous cap (Figure 2b) and shoulder region. Active caspase-3- and TUNELpositive signals were observed in the nuclei of intimal cells mainly in the superficial intima and in and around the lipid core (Figure 2c). OxLDLpositive cells were abundant around the lipid core (Figure 2d) and in the shoulder region as well as fibrous cap.

\section{Group V lesion}

Fibrous connective tissue increased in the plaque, and a few smooth muscle cells positive for alpha-smooth muscle actin were scattered mainly in the thick fibrous cap. A few single-stranded DNA-positive cells were observed in the fibrous cap and around the lipid core including the shoulder region. Double-immunostaining revealed that some single-stranded DNA-positive cells exhibited a positive immunoreaction for HAM56 or alpha-smooth muscle actin. OxLDL-positive cells were distributed predominantly in the region where HAM56-positive cells were present. The results of immunohistochemistry in Group $\mathrm{V}$ resembled those in Group IV, but cells positive for singlestranded DNA, active caspase-3, TUNEL, and oxLDL were less frequently detected in Group $\mathrm{V}$ than in Group IV.

\section{Statistical Analyses}

The average number of single-stranded DNA-positive cells tended to increase sequentially from Group I to IV, and was significantly greater in Group IV than Group I and II $(P<0.01)$ (Figure 3). Moreover, the average number of single-stranded DNApositive cells was significantly smaller in Group V than in Group IV $(P<0.01)$. In addition, the average number of TUNEL-positive cells was significantly greater in Group IV than in the other groups (in Group I, II, III, $P<0.01$ and in Group V, $P<0.05$ ) (Figure 3). The association of the average number of single-stranded DNA-positive cells with the lesion groups was consistent in that of TUNEL-positive cells, and a significant positive correlation was also found between them $(r=0.42, P<0.01)$. The average number of active caspase-3-positive cells was significantly greater in Group IV than Group I and V $(P<0.05)$ (Figure 3), and a significant positive correlation was also found between the average number of single-stranded DNA-positive cells and that of active caspase-3-positive cells $(r=0.38$, $P<0.01)$.

As for the association of the apoptotic macrophage index with the lesion groups, the apoptotic macrophage index was greatest in Group IV among the five groups, being significantly greater than that in Group I and III $(P<0.05)$ (Figure 4$)$. The apoptotic smooth muscle cell index increased sequentially 
a
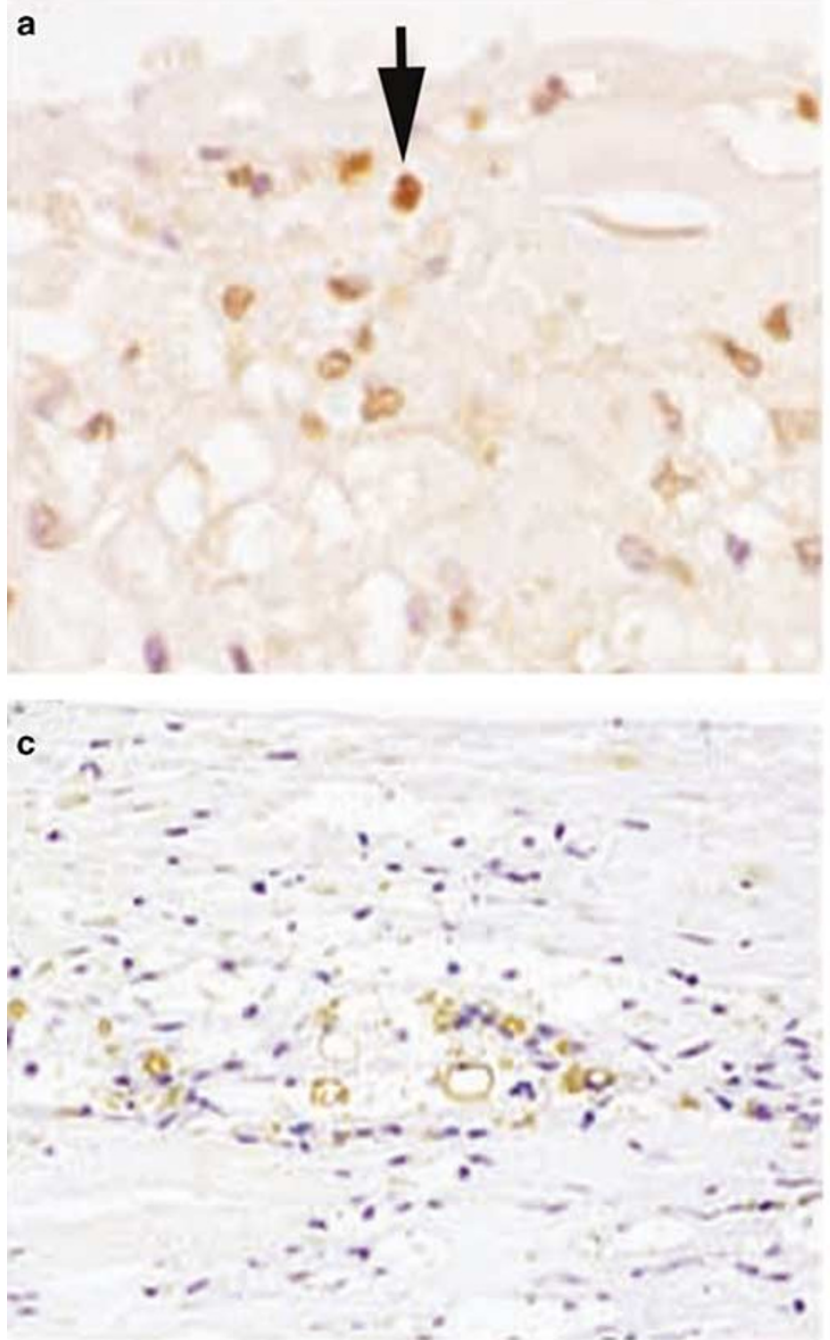

b
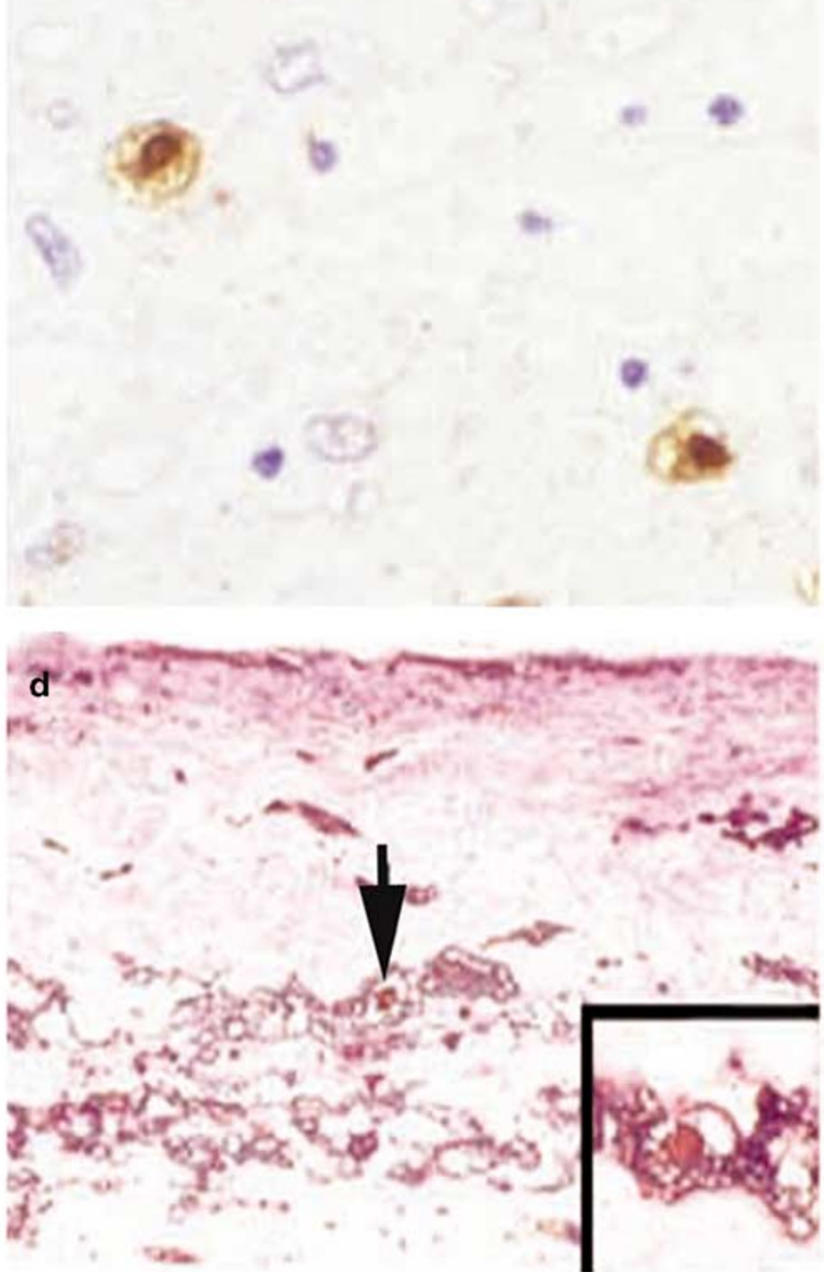

Figure 1 Immunohistochemistry of aortic tissues with a fatty streak (a-d). (a) Single-stranded DNA is expressed in the intimal cells (arrows) located in the superficial area of the fatty streak lesion (magnification $\times 200$ ). (b) Two active caspase-3-positive cells are observed in the intima of the fatty streak (magnification $\times 300$ ). (c) OxLDL is recognized in foam cells of the fatty streak lesion (magnification $\times 150$ ). (d) This figure shows a fatty streak with double-immunostaining using HAM56 antibody and single-stranded DNA antibody. HAM56-positive cells indicating monocyte-derived macrophages (dark blue) are scattered in the intima. Single-stranded DNA is found in the nuclei (brown; arrows) in a few HAM56-positive cells (magnification $\times 130$ ). Inset. High-power view of HAM56-positive cells (dark blue) with single-stranded DNA expression (brown) in the fatty streak (magnification $\times 400$ ).

with atherosclerotic development from Group II to Group IV, and was greatest in Group IV. However, there was no significant difference in the values among the five groups (Figure 4).

Comparison of the apoptotic macrophage index and the apoptotic smooth muscle cell index in each lesion group revealed that the apoptotic macrophage index was significantly greater than the apoptotic smooth muscle cell index in Group II $(P<0.01)$ and Group V $(P<0.05)$. The average number of the apoptotic macrophage index in all intimal lesion groups was significantly greater than that of the apoptotic smooth muscle cell index (the former index; $3.98 \pm 4.51$ vs the latter index; $2.34 \pm 5.21$ : $P<0.05)$.

There was a significant positive correlation between the apoptotic smooth muscle cell index and the average number of oxLDL-positive cells per viewfield by linear regression analysis $(n=32, r=0.53$, $P<0.05$ ), whereas no correlation of the apoptotic macrophage index with the average number of oxLDL-positive cells per one microscopic view-field was demonstrated ( $n=37, r=0.02, P>0.05$ ) (Figure $5)$. These analyses were performed using the specimens positive for single-stranded DNA in intimal smooth muscle cells or macrophages.

\section{Discussion}

In our present study, the number of apoptotic cells positive for single-stranded DNA in the intima increased with atherosclerotic development and reached a peak at the stage of atheroma formation. 

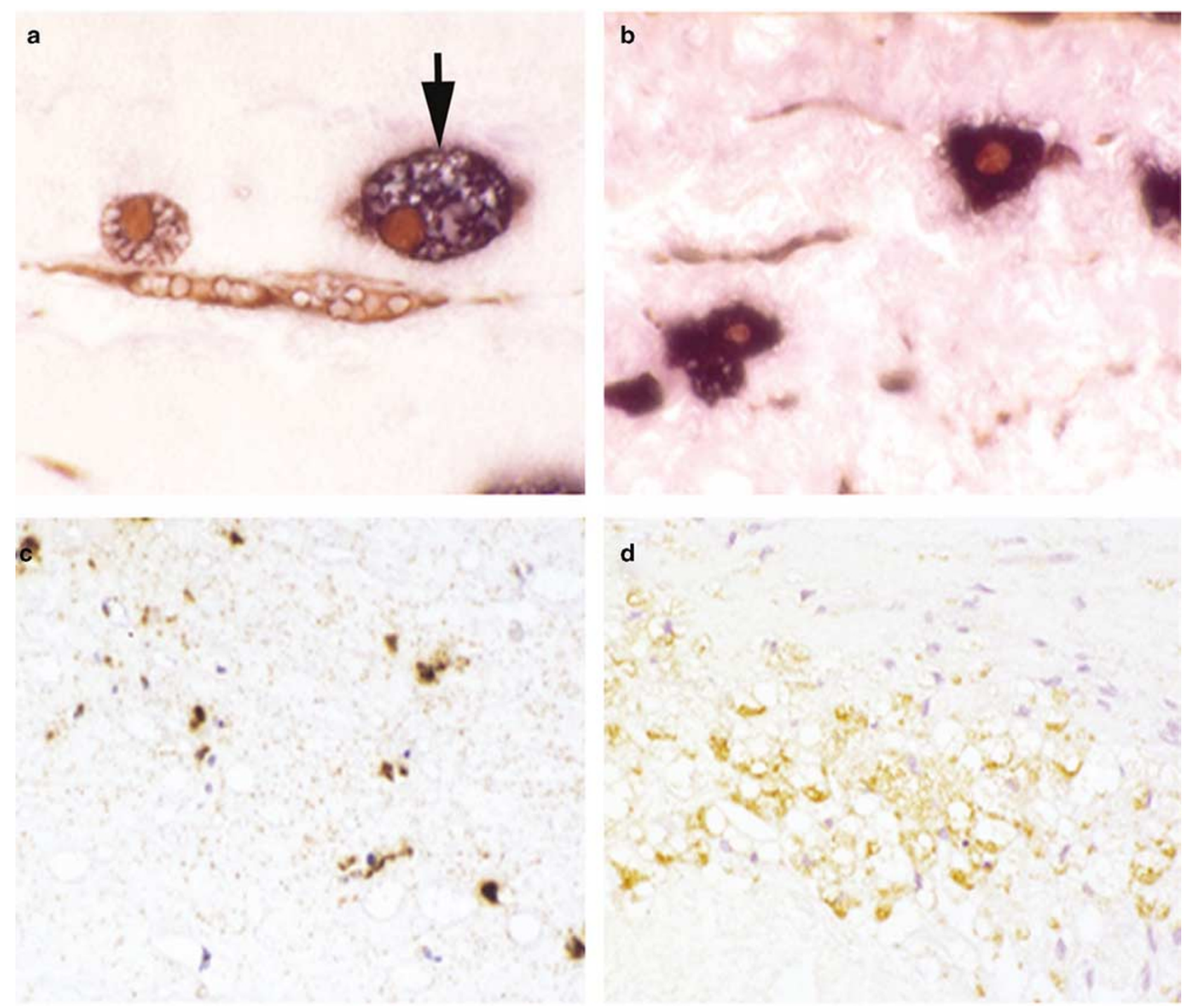

Figure 2 Immunohistochemistry of aortic tissues with an atheroma. (a) shows the cells with double-immunostaining using HAM56 and single-stranded DNA antibodies. An arrow indicates one HAM56-positive cell (dark blue) coexpressed with single-stranded DNA (brown) in a shoulder region (magnification $\times 400$ ). (b) In the fibrous cap of the atheroma, single-stranded DNA-positive nuclei (brown) are found in alpha-smooth muscle actin-positive cells (dark blue) (magnification $\times 400$ ). (c) Active caspase-3-positive cells are observed in a shoulder region of the lesion. (magnification $\times 150$ ). (d) OxLDL is recognized in foamy cells located around the lipid core of the plaque (magnification $\times 150$ ).

Macrophages in the aortic intima were more susceptible to apoptosis than smooth muscle cells throughout the progression of the disease, that is, from Group II to V lesions. As for smooth muscle cells, the number of oxLDL-positive cells significantly correlated with the apoptotic smooth muscle cell index. The results suggest that oxLDL is more intensely involved in triggering the apoptosis of smooth muscle cells than macrophages. The apoptosis of both macrophages and smooth muscle cells thus contributes to the maturation of atherosclerotic lesions, especially the lipid core formation in atheromas.

It is well acknowledged that the TUNEL method hardly detects the beginning of apoptosis. ${ }^{15}$ However, single-stranded DNA (F7-26) antibody is further sensitive enough to detect apoptosis from its beginning. ${ }^{14,15,29}$ In addition, active caspase-3 is one of the most specific inducers of apoptosis and also useful for detection of apoptosis in the early stages. ${ }^{11}$ We placed a priority on single-stranded DNA-positivity as a marker of apoptosis throughout the study because a significant correlation was observed between the average number of singlestranded DNA-positive cells and that of TUNEL- as well as active caspase-3-positive cells. The spatial distribution of apoptotic cells represented by the positivity of single-stranded DNA and active caspase-3 at each stage of atherosclerosis was also quite similar to that derived from the TUNEL method. Therefore, we considered that the specificity of the three antibodies was comparable. 


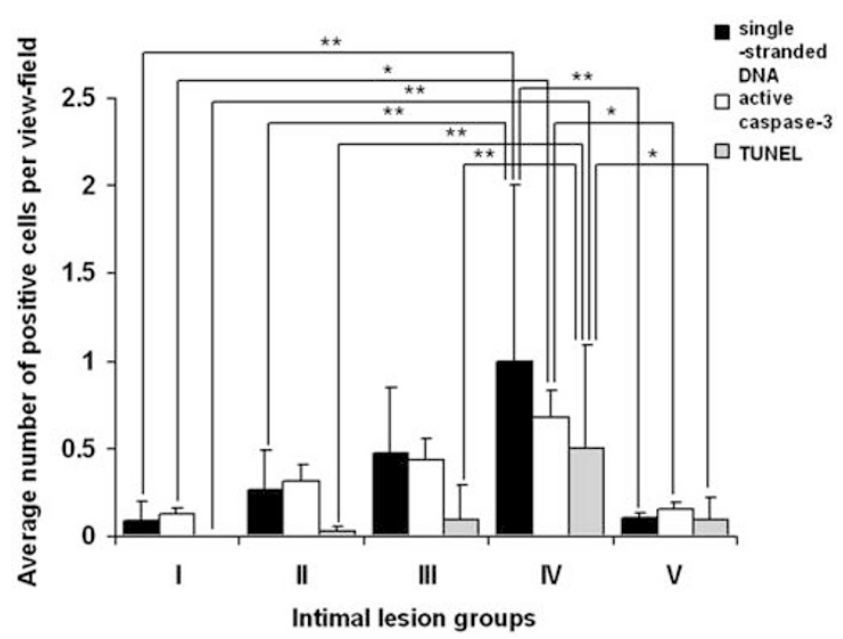

Figure 3 Average number of single-stranded DNA-positive cells, active caspase-3-positive cells, and TUNEL-positive cells per view-field in the intima in the five groups (mean \pm s.d.). The average number of single-stranded DNA (F7-26)-positive cells per view-field: Group I; $0.08 \pm 0.12$, Group II; $0.26 \pm 0.23$, Group III; $0.47 \pm 0.38$, Group IV; $1.00 \pm 1.00$, and Group V; $0.10 \pm 0.03$. The average number of active caspase-3-positive cells per view-field: Group I; $0.12 \pm 0.14$, Group II; $0.31 \pm 0.41$, Group III; $0.43 \pm 0.46$, Group IV; $0.68 \pm 0.53$, and Group V; $0.15 \pm 0.13$. The average number of TUNEL-positive cells per view-field: Group I; $0.00 \pm 0.00$, Group II; $0.03 \pm 0.03$, Group III; $0.09 \pm 0.20$, Group IV; $0.50 \pm 0.59$, and Group V; $0.09 \pm 0.13$. In Group IV, the number of single-stranded DNA-positive cells is significantly greater than that in Groups I and V, and the number of TUNEL-positive cells is also significantly greater than that in the other groups. The number of single-stranded DNA-positive cells was greater than that of TUNEL-positive cells in the five groups. The average number of active caspase-3-positive cells in Group IV is greater than Group I and V. The change in the average number of singlestranded DNA-positive cells with the progression of atherosclerosis shows the same tendency as that of TUNEL-positive cells and active caspase-3-positive cells. Group I; normal, diffuse intimal thickening, and initial lesion, Group II; fatty streak, Group III; preatheroma, Group IV; atheroma, Group V; fibroatheroma and complicated lesions. ${ }^{*} P<0.01,{ }^{*} P<0.05$.

Apoptosis detection using the TUNEL method has hardly shown in the initial lesions of atherosclerosis by previous studies, ${ }^{7-9}$ whereas, in this study, single-stranded DNA-positive cells were detected consistently throughout atherosclerotic development. The discrepancy in the rate of detection in initial lesions, especially fatty streak, between the previous and present results may originate from differences in the methods using single-stranded DNA antibody for detecting apoptotic cells. Apart from this, our results indicated that the average number of single-stranded DNA-positive cells in the intima increased as the atherosclerosis progressed and reached a peak at the atheroma stage. It is thus evident that apoptosis contributes to the overall development of atherosclerosis not only in initial lesions, but also in advanced lesions such as the preatheroma and atheroma.

In this study, apoptotic cells in the fatty streak were distributed in the region where macrophagederived foam cells aggregated. The fatty streak is a

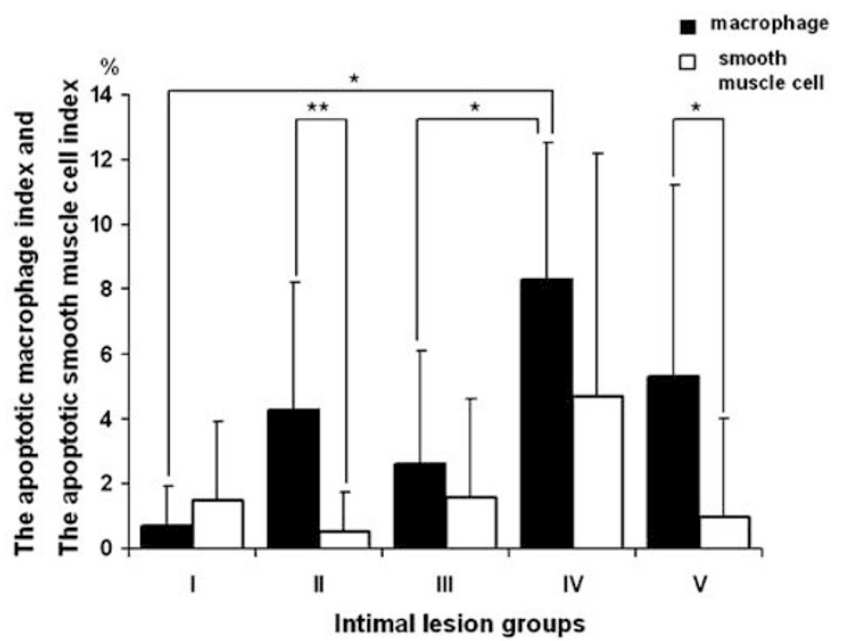

Figure 4 Susceptibility to apoptosis of macrophages relative to intimal macrophages (the apoptotic macrophage index) and that of smooth muscle cells relative to intimal smooth muscle cells (the apoptotic smooth muscle cell index) in the five groups. The apoptotic macrophage index is greatest in Group IV and significantly greater than in Groups I and III. Moreover, the apoptotic macrophage index values in Groups II and V are significantly greater than the apoptotic smooth muscle cell index values. ${ }^{*} P<0.01,{ }^{*} P<0.05$.

precursor of advanced lesions, ${ }^{25,27}$ and the death of lipid-laden macrophages in the arterial intima may result in extracellular lipid deposition through the spread of their contents into the intimal stroma. ${ }^{5}$ In this study, the apoptotic macrophage index value for fatty streak was significantly greater than the apoptotic smooth muscle cell index value. Therefore, the apoptosis of macrophages in the fatty streak probably contributes more to the progression of the disease than the apoptosis of smooth muscle cells. In addition, the average number of the apoptotic macrophage index value for all lesions was also significantly greater that of the apoptotic smooth muscle cell index. Generally, in atheroma lesion, the distribution of macrophages was mainly around lipid core including shoulder region, and that of smooth muscle cells was mainly fibrous cap and shoulder region lesion, and our results were consistent with them. Then, apoptotic cells were detected mainly around extracellular lipid deposits in the advanced lesions, which is consistent with the results of previous studies. ${ }^{7-9}$ Considering the contribution of the death of lipid-laden macrophages to the lipid core formation, ${ }^{30}$ by using more sensitive single-stranded DNA antibody to detect the apopotic cells in any atherosclerotic lesion, our results clearly further clarify that extracellular lipid deposits in the atherosclerotic intima result partly from the apoptosis of foamy macrophages.

In our study, we used oxLDL (FOH1a/DLH3) monoclonal antibody, the epitope of which is the oxidized product of phosphatidylcholine, present in complex structures together with proteins. OxLDL exhibits various biological functions potentially 


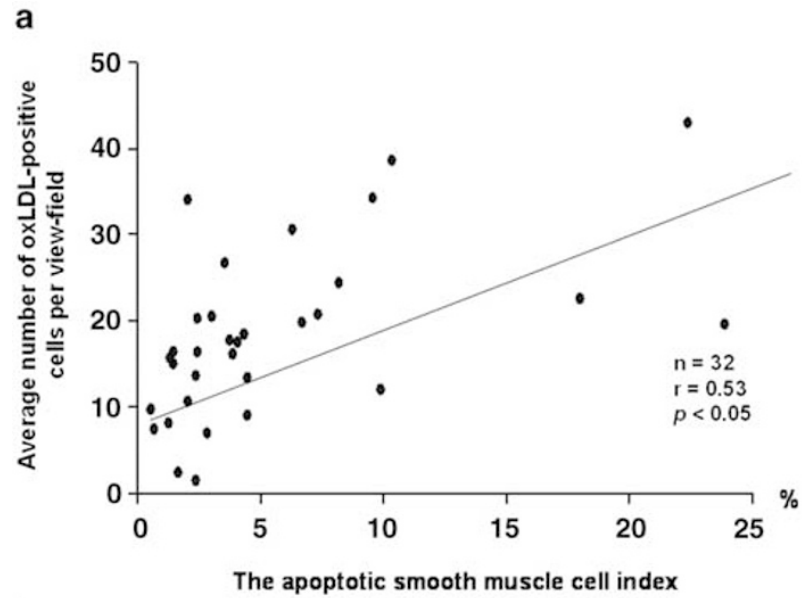

b

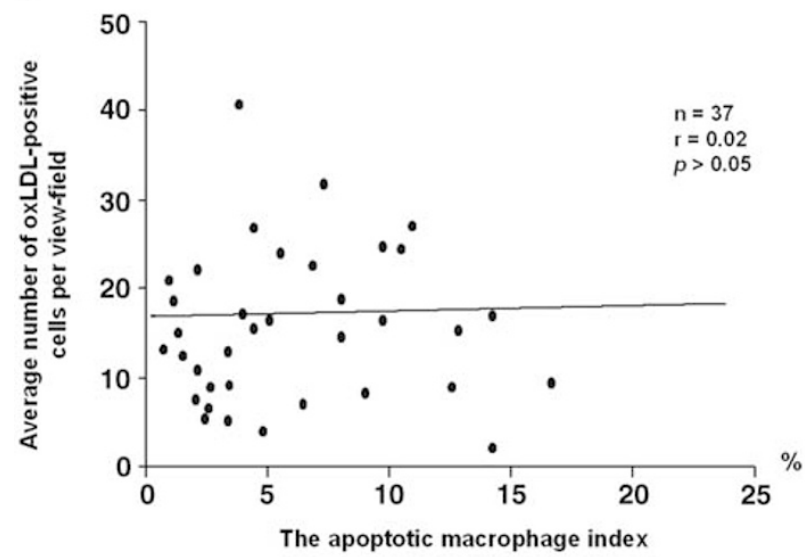

Figure 5 The association between the average number of oxLDLpositive cells per view-field and the apoptotic smooth muscle cell index (a) or the apoptotic macrophage index (b). (a) The apoptotic smooth muscle cell index positively correlates with the average number of oxLDL-positive cells per view-field by linear regression analysis $(r=0.53, P<0.05)$. This analysis was performed using the specimens positive for single-stranded DNA in intimal smooth muscle cells $(n=32)$. (b) In contrast, there is no correlation between the apoptotic macrophage index and the average number of oxLDL-positive cells per view-field $(r=0.02$, $P>0.05)$. This analysis was performed using only the specimens positive for single-stranded DNA in intimal macrophages $(n=37)$.

involved in atherogenesis, such as the induction of adhesion protein expression and subsequent entry of mononuclear cells, formation of foam cells and the fatty streak, and induction of smooth muscle cell migration and proliferation. OxLDL induces apoptosis and necrosis of cultured vascular cells. ${ }^{21}$ Our results indicated that the localization of oxLDLpositive cells resembled that of single-stranded DNA-positive cells and was consistent with that of foam cells over the natural course of human atherosclerosis. By immunohistochemistry, most of the apoptotic macrophages were also demonstrated in the region where many foam cells were present around the lipid core, and this distribution pattern well corresponded with that of oxLDL-positive cells. The apoptotic macrophage index increased with the progression of atherosclerosis, however, no signifi- cant correlation was found between the number of oxLDL-positive cells and the index value. OxLDL has a transient role in the mitogenic effect of macrophages, but finally causes cell death through the induction of apoptosis and necrosis. ${ }^{31,32}$ Several factors such as ischemia, inflammatory cytokines, and the accumulation of toxic substances may also affect cell death in atherosclerotic plaques. ${ }^{11}$ In this study, as for the relation of oxLDL to smooth muscle cell apoptosis, the apoptotic smooth muscle cell index increased with atherosclerotic development, and the apoptotic smooth muscle cells were detected mainly in the shoulder region and fibrous cap, where oxLDL-positive cells were predominant. The increase of smooth muscle cell apoptosis in the plaque will lead to a decrease in quantity of smooth muscle cells and in the biosynthesis of interstitial collagen fibers having a major influence on plaque stability. ${ }^{12}$ The significant quantitative correlation between the number of oxLDL-positive cells and the apoptotic smooth muscle cell index observed in this study is consistent with these findings. Lectin-like oxLDL receptor-1 (LOX-1) mediates oxLDL-induced apoptosis in cultured smooth muscle cells through a Bax/Bcl-2 dependent pathway. ${ }^{33}$ These previous and the present results suggest that smooth muscle cell apoptosis is involved together with the presence of oxLDL and affect the development of atherosclerotic lesions and plaque stability.

\section{References}

1 Munro JM, Cotran RS. The pathogenesis of atherosclerosis: atherogenesis and inflammation. Lab Invest 1988;58:249-261.

2 Stary HC, Chandler AB, Glagov S, et al. A definition of initial, fatty streak, and intermediate lesions of atherosclerosis. A report from the Committee on Vascular Lesions of the Council on Arteriosclerosis, American Heart Association. Arterioscler Thromb 1994;14: 840-856.

3 Ross R. Atherosclerosis-an inflammatory disease. N Engl J Med 1999;14:115-126.

4 Ross R. The pathogenesis of atherosclerosis: a perspective for the 1990s. Nature 1993;362:801-809.

5 Hegyi L, Hardwick SJ, Siow RC, et al. Macrophage death and the role of apoptosis in human atherosclerosis. J Hematother Stem Cell Res 2001;10:27-42.

6 Hegyi L, Skepper JN, Cary NR, et al. Foam cell apoptosis and the development of the lipid core of human atherosclerosis. J Pathol 1996;180:423-429.

7 Kockx MM, De Meyer GR, Muhring J, et al. Apoptosis and related proteins in different stages of human atherosclerotic plaques. Circulation 1998;97:23072315.

8 Lutgens E, de Muinck ED, Kitslaar PJ, et al. Biphasic pattern of cell turnover characterizes the progression from fatty streaks to ruptured human atherosclerotic plaques. Cardiovasc Res 1999;41:473-479.

9 Okura Y, Brink M, Itabe H, et al. Oxidized low-density lipoprotein is associated with apoptosis of vascular smooth muscle cells in human atherosclerotic plaques. Circulation 2000;102:2680-2686. 
10 Bennett MR. Apoptosis of vascular smooth muscle cells in vascular remodelling and atherosclerotic plaque rupture. Cardiovasc Res 1999;41:361-368.

11 Jovinge S, Crisby M, Thyberg J, et al. DNA fragmentation and ultrastructural changes of degenerating cells in atherosclerotic lesions and smooth muscle cells exposed to oxidized LDL in vitro. Arterioscler Thromb Vasc Biol 1997;17:2225-2231.

12 Kockx MM, Herman AG. Apoptosis in atherosclerosis: beneficial or detrimental? Cardiovasc Res 2000;45: 736-746.

13 Kockx MM, Knaapen MW. The role of apoptosis in vascular disease. J Pathol 2000;190:267-280.

14 Frankfurt OS, Krishan A. Identification of apoptotic cells by formamide-induced and denaturation in condensed chromatin. J Histochem Cytochem 2001; 49:369-378.

15 Frankfurt OS, Robb JA, Sugarbaker EV, et al. Monoclonal antibody to single-stranded DNA is a specific and sensitive cellular marker of apoptosis. Exp Cell Res 1996;226:387-397.

16 Berliner JA, Heinecke JW. The role of oxidized lipoproteins in atherogenesis. Free Radic Biol Med 1996;20:707-727.

17 Bjorkerud B, Bjorkerud S. Contrary effects of lightly and strongly oxidized LDL with potent promotion of growth versus apoptosis on arterial smooth muscle cells, macrophages, and fibroblasts. Arterioscler Thromb Vasc Biol 1996;16:416-424.

18 Takahashi K, Takeya M, Sakashita N. Multifunctional roles of macrophages in the development and progression of atherosclerosis in humans and experimental animals. Med Electron Microsc 2002;35:179-203.

19 Escargueil-Blanc I, Salvayre R, Negre-Salvayre A. Necrosis and apoptosis induced by oxidized low density lipoproteins occur through two calcium-dependent pathways in lymphoblastoid cells. FASEB J 1994;8:1075-1080.

20 Itabe H, Takeshima E, Iwasaki H, et al. A monoclonal antibody against oxidized lipoprotein recognizes foam cells in atherosclerotic lesions. Complex formation of oxidized phosphatidylcholines and polypeptides. J Biol Chem 1994;269:15274-15279.

21 Ehara S, Ueda M, Naruko T, et al. Elevated levels of oxidized low density lipoprotein show a positive relationship with the severity of acute coronary syndromes. Circulation 2001;103:1955-1960.

22 Nishi K, Itabe $\mathrm{H}$, Uno $\mathrm{M}$, et al. Oxidized LDL in carotid plaques and plasma associates with plaque instability. Arterioscler Thromb Vasc Biol 2002;22: 1649-1654.

23 Sakata N, Imanaga Y, Meng J, et al. Immunohistochemical localization of different epitopes of advanced glycation end products in human atherosclerotic lesions. Atherosclerosis 1998;141:61-75.

24 Stary HC, Blankenhorn $\mathrm{DH}$, Chandler $\mathrm{AB}$, et al. A definition of the intima of human arteries and of its atherosclerosis-prone regions. A report from the Committee on Vascular Lesions of the Council on Arteriosclerosis, American Heart Association. Arterioscler Thromb 1992;12:120-134.

25 Stary HC, Chandler AB, Dinsmore RE, et al. A definition of advanced types of atherosclerotic lesions and a histological classification of atherosclerosis. A report from the Committee on Vascular Lesions of the Council on Arteriosclerosis, American Heart Association. Circulation 1995;92:1355-1374.

26 Stary HC. Introduction. In: An Atlas of Atherosclerosis and Endothelial Damage: Progression and Regression (Encyclopedia of Visual Medicine). The Parthenon Publishing Group Inc.: New York, ST, 1999, pp 10-12.

27 Homma S, Ishii T, Tsugane S, et al. Different effects of hypertension and hypercholesterolemia on the natural history of aortic atherosclerosis by the stage of intimal lesions. Atherosclerosis 1997;128:85-95.

28 D'Sa-Eipper C, Leonard JR, Putcha G, et al. DNA damage-induced neural precursor cell apoptosis requires p53 and caspase 9 but neither Bax nor caspase 3. Development 2001;128:137-146.

29 Umemura S, Yasuda M, Osamura RY, et al. Enhancement of TdT-mediated dUTP-biotin nick end-labeling (TUNEL) method using mung bean nuclease, a singlestranded DNA digestion enzyme. J Histochem Cytochem 1996;44:125-132.

30 Ball RY, Stowers EC, Burton JH, et al. Evidence that the death of macrophage foam cells contributes to the lipid core of atheroma. Atherosclerosis 1995;114:45-54.

31 Han CY, Pak YK. Oxidation-dependent effects of oxidized LDL: proliferation or cell death. Exp Mol Med 1999;31:165-173.

32 Hardwick SJ, Hegyi L, Clare K, et al. Apoptosis in human monocyte-macrophages exposed to oxidized low density lipoprotein. J Pathol 1996;179:294-302.

33 Kataoka H, Kume N, Miyamoto S, et al. Oxidized LDL modulates Bax/Bcl-2 through the lectinlike Ox-LDL receptor-1 in vascular smooth muscle cells. Arterioscler Thromb Vasc Biol 2001;21:955-960. 